\title{
ECE Declaration on Conservation of Flora, Fauna, and Their Habitats
}

The United Nations Economic Commission for Europe (ECE), at its forty-third session (12-22 April 1988), adopted the following Declaration on Conservation of Flora, Fauna, and their Habitats, as proposed by their Senior Advisers on Environmental and Water Problems:

The ECE member Governments, recalling pertinent provisions of the Declaration of the United Nations Conference on the Human Environment, the aims of the World Conservation Strategy, and recommendations and suggested principles contained in the report, Our Common Future, by the World Commission on Environment and Development, have agreed, by adopting this Declaration, to pursue the following aims:

1. To Conserve living natural resources, in the interests of present and future generations, by maintaining essential ecological processes and life-support systems, preserving genetic diversity, and ensuring sustainable utilization of species and ecosystems;

2. To encourage state, voluntary, and private enterprises, institutions and organizations, and other groups and individuals, to behave with consideration towards Nature and make rational use of its resources;

3. To take the necessary measures to prevent and reduce air, water, and soil, pollution as well as other damage to flora, fauna, and their habitats, directly or indirectly caused by various types of human activity;

4. To give necessary attention to the increasing activities connected with biotechnology and genetic [manipulation] with special reference to game and fish farming, cultivation, and introduction of exotic plant and animal species, in order to avoid damage to wild populations and the environment in general;

5. To improve as necessary, and to implement, national legislation on the conservation of flora, fauna, and their habitats, especially threatened and migratory species;

6 . To provide for the compatibility of economic activities with the natural functioning of ecological systems, in particular through the incorporation of up-to-date environmental considerations into economic activities and social and economic policy-making including land-use planning, and to take necessary administrative, financial, and other, economic measures to protect flora, fauna, and their habitats;

7. To devote all necessary attention to commercial, trade, economic, and aid, practices that bear upon Nature conservation and sustainable development;

8. To strengthen as necessary the existing national and international systems of reserves and other protected $\mathrm{Na}$ ture areas, as well as to improve conservation measures outside these areas;

9. To encourage the activities of voluntary organizations and associations in the conservation of flora, fauna, and their habitats, to promote environmental education and exchange of information, and to foster environmental awareness among all groups of the population;

10. To use more extensively as a matter of priority the existing forms of multilateral and bilateral cooperationsuch as international organizations, conventions, and agreements - to broaden joint efforts for the conservation of flora, fauna, and their habitats in Europe and in neighbouring regions, and to contribute, where necessary or appropriate, to the elaboration of new forms of international cooperation;

\section{On a common European basis:}

- To continue studying and describing the fauna and flora of Europe, including the structure and dynamics of geographical ranges of wild animal and plant species and their genetic diversity in various parts of their ranges;

- To prepare European, regional, and sub-regional, inventories;

- To draw up lists of threatened and migratory species, and of critical habitats;

- To explore the feasibility of elaborating lists of species for which a country, as a range State, has an international responsibility for their conservation, whether or not these species are considered to be endangered in that particular country;

- To develop a programme of information exchange on trends in the status of wild animal and plant species in Europe; and

- To investigate the impact and influence of various economic activities and land-use practices on flora, fauna, and their habitats.

United Nations ECONOMIC COMmission FOR EUROPE

Palais des Nations

1211 Geneva 10, Switzerland.

\section{Royal Geographical Society Support for Expeditions, 1988}

The Royal Geographical Society (RGS), of London, England, UK, has been supporting expeditions for almost 160 years, and has tried, through rigorous screening, to maintain high standards for overseas field research. Recently no fewer than 78 expeditions, with destinations as diverse as Ghana and South Korea, and involving a very wide range of environments and challenges, have been given the Society's formal approval for 1988. The Society's primary motive in approving these expeditions is to advance geographical science.

Financial support totalling over $£ 20,000$ is being awarded to 50 projects. This money comes from the Society's own funds and from a number of sponsors, including a major donation from Barclays Bank in addition to grants from The Geographical Magazine, WEXAS International, RTZ, Rolex, and the Goldsmiths' Company.

Widespread concern about the fate of tropical forests is reflected in the number of expeditions investigating the biological resources of that environment, and in particular local uses of plants. The screening panels were particularly impressed by two projects working in the Brazilian Amazon: The Cambridge Amazon Study Group, carrying out an ecological mapping project on an island near the mouth of the Amazon and Para Amazonia, a ioint Anglo-Brazilian investigation of forest soils and nutrient cycling in an area that is rapidly being settled. Project Soma will collect samples of medicinal and economically important plants that are used by the Orang Kubu people of Central Sumatra.

Several expeditions seek to provide additional information on the status of rare or endangered species in protected areas, and groups from Oxford, Cambridge, and the Open University, will be visiting Madagascar for this purpose. It was interesting to note that almost one-third of the expeditions which applied to the RGS this year are led by women.

In addition to the expeditions approved by the Society, the RGS is currently organizing its own major overseas research initiative with the Linnean Society of London: The Kimberley Research Project, 1988, in the King Leopold and Napier Ranges of Western Australia. Work is also continuing on the Maraca Rain-forest Project, the largest research effort ever organized in Amazonia by any European country, which has just finished its field phase.

\section{SHANE WINSER}

Royal Geographical Society

1 Kensington Gore

London SW7 $2 A R$

England, UK. 